\title{
Deliberation and Research on the Planning and Construction of the New Countryside around Xi'an
}

\author{
Luo Qi \\ Xi'an International University, Xi’an Shaanxi 710077
}

Keyword: Xi'an, Planning and Construction of the New Countryside, Deliberation, Research

\begin{abstract}
In the $5^{\text {th }}$ Plenary Session of the $16^{\text {th }}$ Congress of the Communist Party of China, the strategy of constructing the socialist new countryside was put forward, in order to response the policies of our country, lots of villages have begun to plan and construct their new countryside. The construction of the new countryside is a long term project that needs all the people to plan and to make contributions; it contains several items such as economy, politics, culture, and society etc, so it can not be accomplished at one stroke. As one of the historical and cultural city in China, Xi'an also has begun to construct the new countryside around it so as to response the calling of the government. However, to construct the new countryside is not easy, it is difficult and complex, and it is restricted by lots of the realistic conditions during the process of the construction. Base on these above, this thesis briefly analyzes the general situation about the construction of the new countryside around Xi'an, and the factors that restrict the construction of the new countryside, then put forwards the deliberation and suggestion on the new countryside construction.
\end{abstract}

As the constant development of China, the speed of urbanization becomes faster and faster. Compare with the pervious years, the residential area per capita is increasing remarkably during the constant development and construction of China; it could easily find out the proportion that the storied buildings account for the total buildings is gradually increasing, and it has increased 2.8 percents after the 10th five years plan period. Under this background, in the rural area, the villages, the social organization structure, and the locations of the villages are changing greatly. In general, as the development of urbanization, the population of the countryside, the number of the incorporated villages and the unincorporated village are all decreasing, these effect greatly to the whole economic development and economic structure of China ${ }^{[1]}$. Base on these, the planning and construction of the new countryside becomes the important issue that China is highlighting and supporting. This thesis mainly research on the planning and construction of the new countryside around Xi'an.

\section{The general situation of the planning and construction of the countryside around Xi'an}

Xi'an, which was named Chang'an and Haojing as well in the different period s of the ancient times, is the capital of Shaanxi Province now, and it is one of the famous historical and cultural city in China; it has the complete and profound cultural heritage, and there are many villages that full of distinctive characteristics around the city, and the some time, there are many scenic spots and places of interest. Every year, a lot of tourists come to Xi'an to enjoy the beautiful natural scenery, and the cultural and historical heritages. They also could taste the traditional foods of Xi'an, and feel the local customs. The jurisdiction of Xi'an contains 9 districts and 4 counties, and there are 50 towns, 52 countries, and 3159 villages, the population of the towns and the countries is 3.75 million, the agricultural population is 3.2 million [2]. As the successful close of the 5th Plenary Session of the 16th Congress of the Communist Party of China, in recent years, although there are many projects that aim at planning and constructing the new countryside around $\mathrm{Xi}$ 'an, but in some villages, the construction activities are still spontaneous and they are lack of the further planning and construction. At the some time, some villages are near the city have lost their characteristics gradually because of the development and the expansion of the city, some cultural and historical 
characteristics that has lasted for many years, the places of interest, and the natural scenery are gradually changing or disappearing. What's more, the main industries of the villages are similar, so that the villages become no instinctive characteristics, and they are lack of competitive advantages [3]. Therefore, in the process of the planning and construction of the new countryside, it is necessary to adopt the useful means of planning and controlling to develop the villages under the base of keeping the original cultural and historical resources. It is significant to solve the outstanding contradiction that between the social development and the increasing population, and that between the need of natural resource and the protection of environment. The villages should take the protection of their historical, cultural customs and the natural environment as the first principle, and then to construct the new countryside that is full of special characteristics, so as to improve the life quality of the farmers, and promote the sustainable development of the villages.

\section{The factors that restrict the villages' construction around Xi'an}

The construction of the new countryside is a task that needs the government, the people, and the whole nation to construct together. But, according to the present planning and construction situation of the recent years, although the farmers eager to construct their home land, but they do not participate the construction activities actively; in general, they only join in the activities that was lead by the local government. In the process of the planning and construction, for some farmers with lower educational level and low quality, it is difficult to respond to the relevant calls of the government, and to make the positive interaction, even these activities provoke a lot of contradictions in the process of the construction [4]. Of course, it is not all the farmers' fault. in the exploration of some area, the developers only pay attention to the construction results, but the farmers' wishes; or they just aim for fulfilling the task as fast as possible, while ignore the actual needs of the farmers, so that it reduces the enthusiasm and initiative of the farmers in the construction of the countryside. In addition, there are a lot of problems that restrict the construction of the new countryside such as the farmers incomes can not be constantly kept at a high level, the remainder labors of the rural area can not be transferred to the area where needs the labors, the adjustment of the structure is superficial, the compulsory education in rural area is difficulty, the basic healthy condition is weak, and the social security system is not prefect etc. Only by means of improving the planning and solving these factors which are restrictive can the construction of the new countryside be implemented smoothly.

\section{The deliberation on the construction of the new countryside around Xi'an.}

To inherit and last the local characteristics is not only the important task of the construction and development in the rural areas, but also the important issue of the city and the nation. In Xi'an, The landforms are various, the resource of humanity is rich, and the scenic spots are beautiful and colorful, and they are not only abundant, but also full of historical and cultural backgrounds. And also, lots of revolutionary events were happened in Xi' an, so there are many revolutionary places of interest in Xi'an. From the view of the national strategy, Xi'an has some advantages in traffic conditions; Xi' an locates in the middle of China, and it is the important traffic hub of the country. Base on these, the local government should make the organizations that are dispersive around Xi'an together, and unite the industries such as agriculture, forestry, stockbreeding, and fishery etc, so as to expand the scale of the local production and promote the development of these industries. The government also should respect the subject status of the farmers in the construction abilities; guide the farmers to change their management model from individual management model to market management model. What's more, the government and the farmers should set up the industries with special characteristics and the famous brands, and then propagate them, so as to increase the incomes of the farmers and let them enjoy their comfortable life [5].

Xi'an is the capital of Shaanxi province, although there are many small towns and small villages around it, but these towns and the villages are small and dispersive. The economic driving model that has introduced above is not suitable for the small towns that without characteristic industries 
and characteristic productions, at the some time, the service driving model is lack of complementarities in this respect, and it is difficult to utilize its advantages. Therefore, as the basic skeleton of the construction of the new countryside, to improve the urban system is very important. It is significant to improve the construction of the dispersive towns around Xi'an, at the some time, take the best of the opportunity that the enterprises of the rural area and the small town are been planning and developing, so as to increase the co-movement between the different industries. The developers should design the layout according to the principle that it is important to coordinate the development of the towns and the villages, clarify the position of these towns and villages, and then construct the town system that the core town could drive the development of the surrounding area, so as to let the farmers live in the towns and cities.

The planning and construction of the central village is the key issue of the new rural construction; it is also an effective strategy to make overall arrangement of the rural development, and to promote the adjustment and management of land intensification [6]. During the specific planning and construction process, the designers should choose the village that is large in square and population as the central village; the central village also should have the relative prefect infrastructures and the convenient traffic condition. Specially, the village with beautiful scenery and historical and cultural resources should be explored first, and the designers make a reasonable and overall layout; at last, to build one village as a model that could drive the development of the surrounding villages. To those small villages are lack of developmental resources such as no characteristic industry, small population dispersive, bad traffic conditions, and poor humanity resources, they could move to the large villages that has the better conditions, so as to increasing the working population and develop the characteristic economy rapidly. Nowadays, as the rapid development of science and technology, many new technology tools and technologies have been spread to the countryside, in the development process, the scale of the central village should be expanded according to the actual demand of development, and make sure that the infrastructure of these areas could meet the overall development needs.

An important issue in the planning and the construction of the new countryside is to investigate the land of the rural area, and this needs the understandings and the supports of the farmers. But in the reality, many stubborn problems come into being in this filed. It is the footstone that the farmers take part in the planning and construction, so in the realistic planning, it is inadvisable to doctrinally copy the model of cities so that reduce the farmers' enthusiasm. At the some time, the farmers have the right to know the truth, so the government should answer the questions of the farmers during the process so as to let the farmers join in the construction actively, totally, and deeply. During this process, the village committees should try their best to propagate and demonstrate the significances of the planning and the construction of the new countryside, and to undertake the important task that to organize the farmers to join in the construction. The village committees also have the obligation that to inform the construction results to the farmers, so as to arouse the enthusiasm of the farmers, and construct a better new countryside step by step.

During the process of the planning and construction of the new countryside, it is necessary to optimize the industrial structure and break through the limitations which restrict the farmers' working according to the realistic circumstances of development. In general, the industry in the rural area should more than one kind, it is also necessary to develop the primary industry, secondary industry, and the tertiary industry, so as to avoid the situation that the incomes of farmers are poor because of some special reasons. During the realistic planning and construction, those relative richer villages often have the reasonable industrial structure; base on this, the developers could expand the industrial scale or the developmental scale, and to expand the new countryside from one area to the surrounding area. It is necessary to built the new communities with modern conditions, take the best of the relevance of the economic system, so as to promote the further development of the village and the surrounding area. It is the key point that to plan and construct the villages which have a mean income. The developers should try to develop the labor intensive industry or company on the base of keeping their previous agricultural productivity, so as to acquire the better development without damage to the original economic system. The main industry of the relative 
poorer villages often is agriculture, and the developers should pay more attention to them and give them more support and guidance on agriculture, forestry, stockbreeding, and fishery; in addition, the people of these poor villages could move to the rich villages, enrich the labor force of the rich villages, so as to achieve prosperity together.

In the recent 100 years, because of the wars, the natural calamities, and the political and economic reformation, the rural areas have been changed greatly; the desired land of idyllic beauty has gone away forever. Now, the farmers are constructing their homeland, at the some time, the rural area is developing the relevant industries and their economy, while the city is developing at a faster speed. Under this background, the environment becomes worse and worse, the public begins to pay more attention to the environmental situation. During the process of the planning and construction of the new countryside, the ecology and the environment are the key factors that people should pay more attention to. It is very important to keep the forest. What's more, it is also important to improve the infrastructures such as the road, drainage facility, garbage disposal, management of drink water, etc; these all are the important issues in the construction of the new countryside. To improve the infrastructures could help the economy of the rural area to have a rapid developmental speed, and the good traffic situation could help the farmers to sell their products, so as to increase the farmers' incomes and improve the farmers' life quality.

\section{The example of the new countryside planning and construction in Xi'an}

This thesis takes Shangwang Village that is near Xi'an for example, and briefly introduces the successful experiences that the village has been achieved on the planning and construction of the new countryside. Shangwang Village, which locates to the north of the Qinling Mountains; it belongs to the reaches of Yellow River. The Huangyu River originates from the mountain ridges that is near Shangwang Village, and it flows into the Yang River which is the first tributary of the Wei River. The Tourist Road, which is the most important tourist road in the Chang'an District, it surrounds by the mountains and passes through the village from the north of the village. The village is assembled as a rectangle to the north of the Tourist Road. The advantageous natural environment and the convenient traffic conditions endow the village great developmental potential. There are 163 families, more than 600 residents in the village. Many places of interest are near the village such as The Qinling Wild Animal Zoo, the Huangyu Temple, the Wei Palace, etc. The environment of the village is beautiful; the air there is fresh, birds sing and flowers give forth their fragrance, it is a good place for the urban people to enjoy the leisure time and avoid the summer heat. Based on the geographical advantages, the village committee has caught the developmental opportunities of Qinling Mountains' tourism industry and has built a new countryside with the theme of "farm stay". The village integrates leisure, entertainment, sightseeing with other functions, and attracts many tourists. Now, the Shangwang Village has become a modern tourist small town. The traditional construction of the new village gives people the impression that it is to build a range of new houses, build the wide and plat roads, or the clean and beautiful villages and so on, but the Shangwang Village takes the best of the advantageous geographic advantage, and combines the tourist industry, and then not only improves the hardware facilities, health condition, scenery environment, but also increases the farmers' incomes by means of the advantageous characteristics that come form the "family stay" industry. This case is worth to deliberate by the public, and it provides a new method, which is worth to learn, on the construction of the new countryside.

\section{Acknowledgements}

The Special Funds for Xi'an International University of the Xi'an Social Science Funds.

Project No.: 16IN11

\section{References}

[1] Wang Junping, A Ruhan. Research On the Influence That Is Caused by the Consumption of the 
Rural Residents of Xi'an On the Economic Growth of the Circumjacent City----the Analysis Base on the Spatial Panel Data Model[J]. Journal of Xi'an Shiyou University (Social Science Edition), 2014,06:13-19.

[2] Zhang Jing, Duan Lian. Exploration on the Thinking that Takes the Villagers as the Principal Part in the Villages' Planning and Construction----Take the Planning and Construction of Tianchi Village, Guhua Conuntry, Chongqing For Example[J]. Architecture and Culture, 2015,01:128-130.

[3] Wei Ting. Research on the Characteristics of the Xi'an Rural Residents' Tourism Behaviors and the Influencing Factors[D]. Shaanxi Normal University, 2015.

[4] Wu Miao. Research on the Planning and Construction Model of the New Countryside Construction in Xi'an[D]. Xi'an University of Architecture and Technology, 2009.

[5] Cao Kaining, Yang Dong. The New Countryside Construction Should Show the Local Characteristics----the New Exploration on the New Countryside Construction of Xi'an [J]. Journal of Northwest University (Natural Science Edition), 2011,02:314-318.

[6] Luo Zhengfeng, Li Boshi, Wang Xintong, Che Mengying. Inspiration from the "Shaji Model" That Is about the Rural Information Construction of the Villages around Xi'an [J]. China Rural Science and Technology, 2012,05:49-52. 